\title{
The Organic Acid Profiles in the Feces of Pigs at Brachyspira hyodysenteriae- or B. pilosicoli-Positive Farms
}

\author{
Shong Ji PIAO ${ }^{1)}$, Takamitsu TSUKAHARA ${ }^{1,2)}$, Mitsugi ITOH $^{3)}$, Akira SHIGA ${ }^{4)}$, \\ Yoshikazu ADACHI ${ }^{5}$ and Kazunari USHIDA ${ }^{1) *}$ \\ ${ }^{1)}$ Laboratory of Animal Science, Kyoto Prefectural University, Shimogamo, Kyoto 606-8522, ${ }^{2}$ Kyoto Institute of Nutrition and Pathology, \\ Uji-tawara, Kyoto 610-0231, 3) Akabane Animal Clinic, Tahara, Aichi 441-3502, ${ }^{4}$ Shiga Swine Clinic, Takanabe, Miyazaki $884-0006$ \\ and ${ }^{5)}$ Animal Health Laboratory, School of Agriculture, Ibaraki University, Ami, Ibaraki 300-0393, Japan
}

(Received 11 July 2006/Accepted 19 December 2006)

ABSTRACT. We observed a significant difference in the organic acid profile of diarrheal feces between pigs infected with and free from pathogenic spirochetes. Diarrhea and loose feces were collected from growing pigs, held at 15 different commercial farms. A total of 106 samples were measured for organic acid concentration by HPLC and were checked for the presence of $B$. hyodysenteriae and $B$. pilosicoli by PCR. B. hyodysenteriae was detected in 3 samples collected from one farm. B. pilosicoli was detected in 5 samples collected from another farm. Lower concentrations of iso-butyrate and iso-valerate were likely associated with development of pathogenic spirochete infection.

KEY WORDS: organic acid, pathogenic spirochetes, swine.

J. Vet. Med. Sci. 69(4): 425-428, 2007

Pigs are often infected by two species of pathogenic spirochete, Brachyspira hyodysenteriae and B. pilosicoli. The former causes swine dysentery (SD), which is an economically important diarrheal disease in the swine industry. SDinfected pigs show severe mucohemorrhagic colitis that leads to diarrhea containing blood and mucus and subsequent severe dehydration and growth loss [12]. The latter also causes a diarrheal disease called porcine intestinal spirochetosis. Pigs infected with $B$. pilosicoli have milder colitis and diarrhea than those infected with $B$. hyodysenteriae [12]. However, B. pilosicoli colonizes a broad range of vertebrates, including swine, humans, dogs, and birds [2, 8, 12 , $15,17]$, which makes disease control difficult. Interestingly, there are three non-pathogenic Brachyspira spp. [12, 15], and their distribution and function have not been thoroughly studied. Since a germ-free pig challenged with $B$. hyodysenteriae did not develop SD [11], the etiology of SD cannot be explained by $B$. hyodysenteriae infection alone [12]. Durmic et al. [3] suggested that some intestinal bacteria, such as Bacteroides spp., may be involved in the development of SD. In this context, these authors also suggested that diet-related changes in the large intestinal environment may result in development of SD [3, 4, 13]. However, further studies are needed to demonstrate this hypothesis. In this study, we observed significant differences in the organic acid profiles of diarrheal feces of pigs infected with and free from pathogenic spirochetes.

B. hyodysenteriae ATCC27164 and B. pilosicoli ATCC51139 were used as standard strains. They were cultured on tryptic soy agar (Difco Laboratories, Detroit, MI, U.S.A.) plates supplemented with $5 \%(\mathrm{v} / \mathrm{v})$ defibrinated

\footnotetext{
* Correspondence to: Prof. Ushida, K., Laboratory of Animal Science, Kyoto Prefectural University, Shimogamo, Kyoto 6068522, Japan.
}

horse blood, spectinomycin (400 $\mu \mathrm{g} / \mathrm{mL})$, vancomycin $(25$ $\mu \mathrm{g} / \mathrm{mL})$, and colistin sulfate $(25 \mu \mathrm{g} / \mathrm{mL})[10]$. The plates were placed in an anaerobic jar and cultured at $37^{\circ} \mathrm{C}$. Anaerobiosis was maintained using a GasPak Plus system (BBL, Cockeysville, MD, U.S.A.). Colonies were individually transferred to a Tryptic soy broth medium (Difco Laboratories) supplemented with glucose $(0.5 \% \mathrm{w} / \mathrm{v})$, sodium carbonate $(0.2 \% \mathrm{w} / \mathrm{v})$, L-cystein- $\mathrm{HCl}(0.05 \% \mathrm{w} / \mathrm{v})$, yeast extract $(1.0 \% \mathrm{w} / \mathrm{v}$, Nacalai Tesque, Kyoto, Japan), clarified porcine fecal aqueous extract $(5 \% \mathrm{v} / \mathrm{v})$, and defibrinated horse blood $(5 \% \mathrm{v} / \mathrm{v})$ for culture at $37^{\circ} \mathrm{C}$ for 3 to 5 days according to the method of Kunkle et al. [9]. A fecal aqueous extract was prepared from freshly collected adult sow feces that contained neither antimicrobials nor dietary prebiotics or probiotics. The diet for this sow has been reported previously [19]. Feces were mixed with 4 weights of distilled water and homogenized in a blender. After removal of coarse materials by squeezing through 4 layers of surgical gauze, the liquid was centrifuged at $35,000 \times \mathrm{g}$. The resultant supernatant was autoclaved at $121^{\circ} \mathrm{C}$ for $20 \mathrm{~min}$.

Diarrhea and loose feces were collected just after defecation from growing pigs held at 15 different commercial pig farms. The feces were transported at $4^{\circ} \mathrm{C}$ to Kyoto Prefectural University. A portion of the feces was subjected to determination of water content by drying at $80^{\circ} \mathrm{C}$ for $48 \mathrm{hr}$. Feces with more than $69 \%$ moisture was regarded as diarrheal feces, as described previously [18]. In all, 106 fecal samples were selected as diarrhea or loose stools and subjected to further analyses.

Bacterial DNA was extracted from $0.2 \mathrm{~g}$ of feces according to the method of Godon et al. [6]. DNA was also extracted from pure cultures of two pathogenic Brachyspira by the method of van Hoek et al. [21]. Full-growth cultures of $B$. hyodysenteriae and $B$. pilosicoli were centrifuged at $25,000 \times \mathrm{g}$ at $4^{\circ} \mathrm{C}$ for $10 \mathrm{~min}$. Cell pellets were mixed with 
approximately $0.08 \%(\mathrm{v} / \mathrm{v})$ chelex solution and frozen at $-80^{\circ} \mathrm{C}$ for $20 \mathrm{~min}$. After thawing at ambient temperature, 0.2 vol. of a proteinase $\mathrm{K}$ solution $(10 \mathrm{mg} / \mathrm{mL})$ was added. Tubes were kept at $56^{\circ} \mathrm{C}$ for $4 \mathrm{hr}$ and then at $96^{\circ} \mathrm{C}$ for 10 min. They were then centrifuged at $25,000 \times \mathrm{g}$ at $4^{\circ} \mathrm{C}$ for 10 min to collect the supernatant. The $16 \mathrm{~S}$ rDNA gene of Brachyspira spp. was amplified using the genus-specific primers Br-F (5'-GAGTGACAGTAGATAATGTAAG-3') and Br-R (5'-GGCACTCCTATTTAAATAG AAGC-3') (Table 1). The reaction mixture was constructed with recombinant Taq DNA polymerase (Toyobo, Osaka, Japan) and its antibody for hot-start PCR (Anti-taq high; Toyobo). Each $50 \mu \mathrm{L}$ PCR mixture contained $10 \mathrm{mM}$ Tris- $\mathrm{HCl}(\mathrm{pH}$ 8.3), $50 \mathrm{mM} \mathrm{KCl}, 1.5 \mathrm{mM} \mathrm{MgCl} 2,0.2 \mathrm{mM}$ each deoxynucleoside triphosphate (dNTP), 5U recombinant Taq DNA polymerase, $2 \mathrm{U}$ anti-taq high, $0.4 \mu \mathrm{M}$ of each primer, and $50 \mathrm{ng}$ template DNA. The samples were amplified in a thermal cycler (TaKaRa PCR Thermal Cycler MP, TaKaRa, Kyoto, Japan) using the following program: initial denaturation at $95^{\circ} \mathrm{C}$ for $4 \mathrm{~min} ; 35$ thermal cycles of $95^{\circ} \mathrm{C}$ for 45 sec, $58^{\circ} \mathrm{C}$ for $45 \mathrm{sec}$, and $72^{\circ} \mathrm{C}$ for $60 \mathrm{sec}$; and final elongation at $72^{\circ} \mathrm{C}$ for $7 \mathrm{~min}$. The $B$. hyodysenteriae tly $A$ gene was amplified using the primers reported by Fellstrom et al. [5]. The PCR conditions were the same as above except for the annealing temperature, which was $56^{\circ} \mathrm{C}$. Two B. pilosicoli 16S rDNA gene-specific primers were constructed, Bp-F (5'-GTAGAGGAAAGTTTTTT CGCTTC-3') and Bp-R (5'-GGCACTCCTATTTAAATAGAAGC-3') (Table 1). The PCR conditions were the same as above except for the annealing temperature, which was $54^{\circ} \mathrm{C}$. The size of the PCR products was confirmed by analyzing $5 \mu \mathrm{L}$ samples using $1 \%$ agarose gel $(\mathrm{w} / \mathrm{v})$ electrophoresis and ethidium bromide staining. The partial sequence (ca. $500 \mathrm{bp}$ ) of the amplified product was determined for each primer set on 2 fecal samples and a pure culture of $B$. hyodysenteriae and $B$. pilosicoli after TA cloning to check the validity of the PCR conditions used. TA-cloning subsequent sequencing was conducted as described previously [7].

The organic acid concentration was determined by ionexclusion HPLC, as described previously [20]. The organic acid concentrations were analyzed by one-way ANOVA or the Kruskal-Wallis test to compare the values taken from feces with pathogenic spirochetes with those from feces free from pathogenic spirochetes. Scheffe's post hoc comparison was used for multiple comparisons when needed. All data were analyzed using StatLight 2000 [16]. Differences among means were considered significant at $\mathrm{p}<0.05$.

Genus-specific PCR detection for Brachyspira spp. was positive for 21 samples. The $B$. hyodysenteriae tly $A$ gene was detected in only 3 of the 21 Brachyspira spp.-positive feces. B. pilosicoli $16 \mathrm{~S}$ rDNA was detected in 5 of the 21 Brachyspira spp.-positive feces (Table 2). There were no feces in which both pathogenic Brachyspira were simultaneously present. Only one farm was $B$. hyodysenteriae-positive, and only one farm was $B$. pilosicoli-positive.

The correlations between the fecal organic acid concentrations and the presence of pathogenic Brachyspira are shown in Table 2. The concentration of iso-butyrate was

Table 1. Primers used in this study

\begin{tabular}{llll}
\hline Gene & & Primer pairs & References \\
\hline \multirow{2}{*}{ Brachyspira 16S rDNA } & Forward & 5'-GAGTGACAGTAGATA ATGTAAG-3' & This study \\
& Reverse & 5'-GGCACTCCTATTTAA ATAGAAGC-3' & This study \\
B. hyodysenteriae tyl A & Forward & 5'-GCAGATCTAAAGCACAGGAT-3' & {$[5]$} \\
& Reverse & 5'-GCCTTTTGAAACATCACCTC-3' & {$[5]$} \\
B. pilosicoli 16S rDNA & Forward & 5'-GTAGAGGAAAGTTTTTCGCTTC-3' & This study \\
& Reverse & 5'-GGCACTCCTATTTAAATAGAA GC-3' & This study \\
\hline
\end{tabular}

a) Genus-specific primers.

Table 2. Organic acid concentrations in the feces of pigs infected with Brachyspira spp. ${ }^{\text {a) }}$

\begin{tabular}{|c|c|c|c|c|c|c|c|c|c|c|}
\hline \multirow{2}{*}{\multicolumn{2}{|c|}{$\begin{array}{l}\text { PCR detection of Number of } \\
\text { Brachyspira fecal samples }\end{array}$}} & \multicolumn{9}{|c|}{ Organic acid concentration (mmol $/ \mathrm{kg}$ wet feces) } \\
\hline & & Succinate & Lactate & Formate & Acetate & Propionate & iso-Butyrate & n-Butyrate & iso-Valerate & n-Valerate \\
\hline Not detected & 85 & $0.2 \pm 0.8$ & $5.4 \pm 13.6$ & $1.0 \pm 0.7$ & $94.8 \pm 23.7$ & $46.1 \pm 21.3$ & $4.2 \pm 2.4 \mathrm{a}$ & $27.3 \pm 18.0$ & $4.9 \pm 3.1 b$ & $10.0 \pm 6.9$ \\
\hline B. hyodysenteriae & 3 & $0.0 \pm 0.0$ & $6.9 \pm 5.7$ & $0.9 \pm 0.1$ & $95.0 \pm 12.6$ & $37.7 \pm 1.1$ & $2.6 \pm 1.6 b$ & $13.5 \pm 3.0$ & $3.8 \pm 1.7 \mathrm{bc}$ & $5.5 \pm 2.1$ \\
\hline B. pilosicoli & 5 & $0.3 \pm 0.3$ & $3.4 \pm 3.7$ & $0.8 \pm 0.3$ & $99.6 \pm 11.6$ & $40.9 \pm 15.7$ & $2.1 \pm 0.6 b$ & $19.7 \pm 7.5$ & $1.6 \pm 1.0 \mathrm{c}$ & $5.8 \pm 2.7$ \\
\hline Non-pathogenic & $13^{\mathrm{b})}$ & $0.1 \pm 0.2$ & $2.9 \pm 4.0$ & $1.2 \pm 0.8$ & $110.8 \pm 14.5$ & $49.6 \pm 17.2$ & $7.0 \pm 2.9 \mathrm{a}$ & $28.9 \pm 14.8$ & $8.1 \pm 3.4 \mathrm{a}$ & $11.1 \pm 6.3$ \\
\hline \multicolumn{11}{|l|}{ Brachyspira spp. } \\
\hline $\begin{array}{l}\text { One-way ANOV } \\
\text { Kruskal-Wallis te }\end{array}$ & $\begin{array}{l}\text { VA or } \\
\text { test } p \text { value }\end{array}$ & N.C. & 0.44 & 0.83 & 0.12 & 0.78 & $<0.001$ & 0.32 & $<0.001$ & 0.32 \\
\hline
\end{tabular}

a) Values are the means $+/-$ SD.

The means in a column without a common letter differ significantly (abc; $\mathrm{p}<0.05$ ).

b) The number of feces carrying B. hyodysenteriae or B. pilosicoli was subtracted from the number of feces carrying Brachyspira spp. as determined by Brachyspira genus-specific PCR. 
Table 3. Organic acid concentration in the pig feces collected from farms contaminated with pathogenic Brachyspira ${ }^{\text {a) }}$

\begin{tabular}{|c|c|c|c|c|c|c|c|c|c|c|c|}
\hline \multirow{2}{*}{$\begin{array}{l}\text { Pathogenic } \\
\text { Brachyspira }\end{array}$} & \multirow{2}{*}{$\begin{array}{c}\text { Number of } \\
\text { farms }\end{array}$} & \multirow{2}{*}{$\begin{array}{l}\text { Number of } \\
\text { feces analyzed }\end{array}$} & \multicolumn{9}{|c|}{ Organic acid concentration ( $\mathrm{mmol} / \mathrm{kg}$ wet feces) } \\
\hline & & & Succinate & Lactate & Formate & Acetate & Propionate & iso-Butyrate & n-Butyrate & iso-Valerate & n-Valerate \\
\hline Not detected & 13 & 87 & $0.2 \pm 0.8$ & $4.8 \pm 12.8$ & $1.1 \pm 0.8$ & $98.8 \pm 22.6 \mathrm{a}$ & $48.0 \pm 21.1 \mathrm{a}$ & $4.8 \pm 2.6 \mathrm{a}$ & $29.1 \pm 17.6 \mathrm{a}$ & $5.7 \pm 3.3 \mathrm{a}$ & $10.6 \pm 7.0 \mathrm{a}$ \\
\hline $\begin{array}{l}\text { B. hyodysenteriae- } \\
\text { positive farm }\end{array}$ & e- & 8 & $0.1 \pm 0.2$ & $10.6 \pm 13.2$ & $0.7 \pm 0.3$ & $80.8 \pm 27.8 \mathrm{a}$ & $33.4 \pm 12.7 \mathrm{a}$ & $1.8 \pm 1.1 \mathrm{~b}$ & $13.4 \pm 9.7 \mathrm{~b}$ & $2.5 \pm 1.4 \mathrm{~b}$ & $6.3 \pm 4.8 \mathrm{~b}$ \\
\hline $\begin{array}{l}\text { B. pilosicoli- } \\
\text { positive farm }\end{array}$ & 1 & 11 & $0.2 \pm 0.2$ & $7.9 \pm 17.2$ & $0.8 \pm 0.3$ & $87.5 \pm 22.9 \mathrm{a}$ & $37.2 \pm 13.2 \mathrm{a}$ & $2.4 \pm 1.2 \mathrm{~b}$ & $15.5 \pm 8.5 b$ & $2.3 \pm 1.7 \mathrm{~b}$ & $5.4 \pm 2.5 \mathrm{~b}$ \\
\hline \multicolumn{3}{|c|}{$\begin{array}{l}\text { One-way ANOVA or } \\
\text { ruskal-Wallis test } p \text { value }\end{array}$} & 0.31 & 0.88 & 0.47 & 0.047 & 0.049 & $<0.001$ & 0.002 & $<0.001$ & 0.02 \\
\hline
\end{tabular}

a) Values are the means $+/-\mathrm{SD}$.

The means in a column without a common letter differ significantly $(a b ; p<0.05)$.

significantly lower in the feces containing the pathogenic Brachyspira than in those free from Brachyspira spp. The concentration of iso-valerate was also lower in the feces containing the pathogenic Brachyspira than in those free from Brachyspira spp. On the other hand, the feces with non-pathogenic Brachyspira detected a higher concentration of these acids than those free from Brachyspira spp. (Table 2). Other organic acids were not affected, with or without pathogenic spirochete infection. Comparison of the organic acid concentrations of the feces sampled from the farm with 3 pigs infected with $B$. hyodysenteriae with those of the farms free from pathogenic Brachyspira (Table 3) showed that the feces taken from the infected farm contained lower iso-butyrate and iso-valerate concentrations than those of the non-infected farms. The same tendency was observed for the feces taken from the farm in which 5 pigs were infected with B. pilosicoli. The concentrations of n-butyrate and n-valerate were also lower in the feces from the pathogenic Brachyspira-positive farms than in those from the non-infected farms.

The large-intestinal environment of pigs reflects the development of SD [3, 4, 13]. Rapidly fermentable carbohydrates, such as guar gum, are linked to clinical expression of SD [13], whereas a high animal-protein diet is protective against SD [14]. In this study, lower concentrations of isobutyrate and iso-valerate were associated with development of pathogenic spirochete infections. Interestingly, the feces collected from the two farms where pigs were infected with pathogenic Brachyspira showed lower iso-butyrate and isovalerate concentrations than those collected from noninfected farms. iso-Butyrate and iso-valerate are organic acids that are produced by deamination of branched chain amino acids, such as valine and leucine [1]. A lower concentration of these iso-acids, therefore, suggests lower activity of bacterial deamination and/or a smaller supply of branched chain amino acids. In this context, protection against SD by feeding a high animal-protein diet [14] seems interesting. It is noteworthy that the farm in which 3 pigs were infected with $B$. hyodysenteriae used a diet consisting of waste bred $(50 \%)$ and a commercial swine formula feed $(50 \%)$. It appears that this diet was richer in rapidly fermentable carbohydrates than the commercial formula feed only. The pigs on this farm were fed this particular diet from weaning to finishing. The present observation suggests the importance of the animal-protein concentration in the swine diet, in which low protein and highly fermentable carbohydrates may support colonization by $B$. hyodysenteriae. This point requires further elucidation. On this farm, SD has been observed for a long time, particularly in midsummer, and B. hyodysenteriae has also been detected. Consistent detection can be related to the particular diet formulation used on this farm. The other farm contaminated by B. pilosicoli had once suffered from SD caused by B. hyodysenteriae. Since a typical formula feed with no modifications was used on this farm, it was difficult to determine why there were lower concentrations of iso-acids. This farm was free from $B$. hyodysenteriae by the start of sampling in this study, and non-pathogenic Brachyspira spp. and/or weakly pathogenic Brachyspira (B. pilosicoli) apparently replaced $B$. hyodysenteriae. The reasons and mechanisms for this replacement are unknown. However, Moxley and Duhamel [12] suggested in a review article that colonization by non-pathogenic Brachyspira would be effective for prevention of colonization by pathogenic Brachyspira. The possibility of competitive exclusion by non-pathogenic Brachyspira should be studied in detail in further studies because such evidence can develop an alternative treatment for preventing infection and colonization by $B$. hyodysenteriae.

ACKNOWLEDGEMENTS. The authors thank Mr. Nobuo Nakanishi and Mr. Kyota Utsumi for sampling the pig feces. Suggestions from Dr. Kazuma Kudo (Chuo Liverstock Hygiene Service Center, Akita city, Akita 011-0904, Japan) are also greatly acknowledged.

\section{REFERENCES}

1. Chen, G. J. and Russell, J. B. 1989. Appl. Environ. Microbiol. 55: 2658-2663.

2. De Smet, K. A. L., Worth, D. E. and Barrett, S. P. 1998. Int. J. Syst. Bacteriol. 48: 1257-1263.

3. Durmic, Z., Pethick, J. R., Pluske, J. R. and Hampson, D. J. 1998. J. Appl. Microbiol. 85: 574-582.

4. Durmic, Z., Pethick, D. W., Mullan, B. P., Schulze, H., Accioly, J. M. and Hampson, D. J. 2000. J. Appl. Microbiol. 89: 678-686. 
5. Fellstrom, C., Zimmerman, U., Aspan, A. and Gunnarsson, A. 2001. Anim. Health Res. Rev. 2: 37-43.

6. Godon, J. J., Zumstein, E., Dabert, P., Habouzit, F. and Moletta, R. 1997. Appl. Environ. Microbiol. 63: 2802-2813.

7. Inoue, R. and Ushida, K. 2003. FEMS. Microbiol. Ecol. 46: 213-219.

8. Jensen, T. K., Moller, K., Boye, M., Leser, T. D. and Jorsal, S. E. 2000. Vet. Pathol. 37: 22-32.

9. Kunkle, R. A., Harris, D. L. and Kinyon, J. M. 1986. J. Clin. Microbiol. 24: 669-671.

10. La, T., Phillips, N. D. and Hampson, D. J. 2003. J. Clin. Microbiol. 41: 3372-3375.

11. Meyer, R. C., Simon, J. and Byerly, C. S. 1974. Vet. Pathol. 11: $515-526$.

12. Moxley, R. A. and Duhamel, G. E. 1999. pp. 83-101. In: Mechanisms in the Pathogenesis of Enteric Diseases 2, ed. (Paul, P. S. and Francis, D. H. eds.), Kluwer Academic/Plenum Publishers, New York.

13. Pluske, J. R., Durmic, Z., Pethick, D.W., Mullan, B. P. and Hampson, D. J. 1998. J. Nutr. 128: 1737-1744.

14. Pluske, J. R., Siba, P. M., Pethick, D. W., Durmic, Z., Mullan, B. P. and Hampson, D. J. 1996. J. Nutr. 126: 2920-2933.

15. Rohde, J., Rothkamp, A. and Gerlach, G. F. 2002. J. Clin. Microbiol. 40: 2598-2600.

16. StatLight Users Manuals. 2004. Yckms. Co., Ltd., Tokyo (in Japanese).

17. Tasu, C., Tanaka, T., Tanaka, T. and Adachi, Y. 2004. J. Vet. Med. Sci. 66: 875-877.

18. Tsukahara, T. and Ushida, K. 2001. J. Vet. Med. Sci. 63: 13511354.

19. Tsukahara, T., Koyama, H., Okada, M. and Ushida, K. 2002. J. Nutr. 132: 2229-2234.

20. Ushida, K. and Sakata, T. 1998. Anim. Sci. Technol. (Jpn.) 69: 100-107.

21. van Hoek, A. H., van Alen, T. A., Sprakel, V. S., Hackstein, J. H. and Vogels, G. D. 1998. Mol. Biol. Evol. 15: 1195-1206. 